社会的自立性と犯罪深度を基にした連続放火犯の分類と分類別にみた放火形態について

\author{
財津 亘 \\ 富山県警察本部刑事部科学捜査研究所 \\ 干930-8570 富山県富山市新総曲輪 1 番 7 号
}

\title{
Offence Characteristics of Serial Arsonists, Differentiated by Their Social Independence and Severity of Criminality
}

\author{
Wataru Zaitsu \\ Forensic Science Laboratory, Toyama Prefectural Police Headquarters \\ 1-7 Shin-Sougawa, Toyama-shi, Toyama 930-8570, Japan
}

(Received 7 August 2009; accepted 14 April 2010)

\begin{abstract}
Serial arsonists $(N=125)$ were differentiated into four groups on the basis of their social independence and the degree of criminality, by using categorical principal components analysis (CATPCA). Results indicated the following. (1) Arsonists with high social independence and high criminality were aged 40 years or more in age, did not live with their parents, and tended to have criminal records for theft. (2) Arsonists with high social independence and low criminality were most frequently employed, high school graduates, married, and had no criminal record. Moreover, there were more female and mental patients in this group compared with other groups. (3) Arsonists with low social independence and high criminality were all male, compulsory education level (including high school dropouts), unmarried, not living with parent $(\mathrm{s})$, and had no criminal record of theft. These arsonists tended to have relatively no criminal record of arson compared with other groups. (4) Arsonists with low social independence and low criminality were the youngest among four groups and were aged between 10 and 30 years, unmarried, lived with their parent (s), and had no criminal record. Results of log-linear analysis indicated that arsonists with high social independence tended to use a car or walk to the crime scene, whereas those with low social independence were inclined to use a bicycle. Moreover, arsonists with high criminality records tended to prepare the medium for arson in advance and drink alcohol before the offence, whereas arsonists with low criminality had a tendency to set fire to the same place repeatedly.
\end{abstract}

Key words: Serial arson, Categorical principal components analysis (CATPCA), Log-Linear Model, Social independence, Degree of criminality 


\section{緒 言}

犯人像推定研究では犯罪行動（Action）と犯罪者 の特徵（Characteristics）との関連性を見出すこと が重要となる。このような関連性を見出す研究はそ の頭文字から $\mathrm{A}-\mathrm{C}$ 研究とされる ${ }^{1)}$. また, 犯人像 推定は犯罪者の犯罪行動などから犯人像を推定する 性質上，犯罪行動を中心に分析した研究が多い. 本 研究の分析対象である放火犯罪についても, 近年放 火形態を多変量解析によって類型化することで放火 犯罪を包括的に捉えるといった研究がいくつかみら れる ${ }^{2-5)}$. Canter and Fritzon ${ }^{2)}$ は最小空間分析 (Small Space Analysis: SSA) と呼ばれる多变量解析 を用いて, 関連の強い複数の放火形態を放火の対象 と犯行動機といった側面でまとめ，4つの犯行テー マ（表出的対人放火 - 道具的対人放火 - 表出的対物 放火・道具的対物放火）を見出した．対人放火とは 自己若しくは他者に対する放火を意味し，脅迫や自 宅に放火するといった行動と相関が高いとされる. また，対物放火とはその名のとおり物に対する放火 で公共施設などが対象となることが多い. 表出的動 機による放火とは，感情の表出など心理的要因によ る放火を意味する。一方，道具的動機による放火と は他者を傷つける若しくは窃盗など他の犯罪を隠蔽 するためといった，目的を達成するための放火のこ とである。Canter and Fritzon ${ }^{2}$ は道具的対物を テーマとした放火犯は若年層が多く，表出的対人を テーマとした放火犯には精神疾患による通院歴を有 する者が多いといった犯人像を提示している。ま た, Santtila et al. ${ }^{3)}$ は未成年者の放火形態から， Canter and Fritzon ${ }^{2)}$ と同様の類型を確認してい る. 我が国については, Wachi et al.4,5) が男性と女 性の連続放火犯について検討しており，犯行テーマ （表出的・道具的）と移動距離との関連について言 及している。

このように, 犯人像推定研究では犯罪行動を中心 に分析して犯人像を提示する研究が多い.しかし， 我が国の連続放火研究4,5)では, 放火形態から犯行 テーマ（表出的・道具的）は見出せたものの，放火 犯を男女別で見た場合には，犯行テーマと放火犯属 性 (年齢, 犯罪歴, 婚姻状態, 同居, 最終学歴, 就
業状態）の間に明確な関連性はみられなかった。こ のように，放火形態を中心とした分析で $\mathrm{A}-\mathrm{C}$ の関 連性が見出せない場合，放火犯そのものを類型化す るなど異なる視点で放火犯罪を分類する必要があろ う.

放火犯を分類した研究は犯罪心理学の分野におい て古くから行われているが，それは主に事例を詳細 に検討し，犯人の供述などに基づいて犯行動機を見 出し，それを基にした類型が多い。例えば，中田6) は犯行動機に基づき, 復售, 犯行の隠蔽, 利得欲, 犯行の容易化，逃走，自殺，性的·色情関係，羡 望，復縁の願望，保険金詐欺といった分類を行って いる。また，桐生7)によると放火は田舎型と都市型 に分けられ，その下位概念として放火犯の犯行動機 を基に，痴情型・利益型・副次型に分類できるとい う。痴情型とは男女間の痴情関係のもつれによる放 火で，利益型は保険金詐欺を目的とした放火，最後 の副次型は犯行を隠蔽ないし容易化するための放火 としている，ただし，上位概念の田舎型放火と都市 型放火といった分類はどちらかというと放火形態か らの分類といえる。 また，前述のCanter and Fritzon $^{2}$ や Wachi et al. ${ }^{4,5}$ ) も犯行動機（表出的 · 道 具的）によって放火を分類しているが，犯行動機は あくまで複数の放火形態を包括的に捉えた結果とし て解釈されたものである.

犯行動機という概念については次のような指摘が されている．第 1 に，犯行動機を確認する方法がな い上に，犯罪者自身がその犯行動機を理解していな い場合があるとされる ${ }^{8)}$. 第 2 に，放火犯の犯行動 機は知能や性格など「個人的要因」と対人関係の状 態や経済状態といった「環境的要因」が複雑に錯綜 して形成されていることから，単一の要因で説明す るのは難しいという9). 第 3 に，放火犯の犯行動機 は連続放火の過程で変化することもあるという。例 えば，上野9)は「不満の発散」 $\rightarrow\lceil$ 怨恨・憤怒」 $\rightarrow\lceil 火$ 事騒ぎ」という異種動機への変遷事例を紹介してい る.これに対して，放火犯の性別や犯罪歴といった 属性は, 犯行動機と異なり, 曖昧でないと同時に比 較的変化しにくい。しかし，このような放火犯の属 性データを多变量解析によって客観的に分析して連 続放火犯を分類し，類型間の放火形態を検討した実 
証的な $\mathrm{A}-\mathrm{C}$ 研究はみられない.

そこで, 本研究では我が国における連続放火犯の 諸属性を基に多变量解析を行い，探索的に連続放火 犯を分類し，得られた連続放火犯の類型と放火形態 との関連性を見出すことで，連続放火犯に関する基 礎的な知見を深めることを目的とした。

\section{方 法}

\section{データ}

1975年から2008年までの間に，連続放火事件に及 んで検挙された125名に関する事件資料を次に述べ る条件の下でランダムに収集した。事件資料は 5 件 以上の放火に及んだ単独犯の及を対象とし，全国を 母集団として收集した，その結果，データは27府県

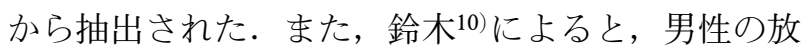
火犯の場合，年齢層が上がるにつれてスプリー放火 （犯行に冷却期間がなく，短時間に複数放火に及ぶ こと）の割合が高くなるという。つまり，スプリー 放火と連続放火の放火犯は質的に異なる可能性があ る. そこで，本研究では事件資料の収集過程で，又 プリー放火に及んだ者の事件資料は除いた。

な抢，本研究で用いたデータを先行研究のデー タ9,11,12) と比較したところ，本データにおいて自動 車を使用した放火犯の割合が高かったことを除き， 先行研究で見出されている特徵と大きな違いはみら れなかった。

\section{放火犯属性}

収集した事件資料を基に，次の変数を用いて， データを作成した．本研究で扱った放火犯の属性に 関する変数は, (1)性別, (2)年齢, (3)就業状態, (4)最 終学歴, (5)婚姻状態, (6)子供, (7)親との同居, (8)精 神疾患および知的障害，(9)契煙習慣，(10)放火歴，(11) 㘯盗歴の11变数である.

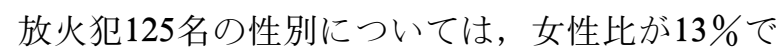
あった。

連続放火犯の平均年齢は35.0歳（SD=13.5）で, 中央值が 32.0 歳, 範囲は14歳から79歳であった. 年 代別でみると10代が 15 名（12\%），20代が34名（27 \%)，30代が29名 (23\%)，40代が25名（20\%)，50 代以上が22名 (18\%) であった。 また，本研究では 年齢をこの 5 つの分でコード化した後に分析し
た。

就業状態については, 有職者が74名 (59\%), 無 職者が44名 (35\%), 学生が 7 名 (6\%) であった。 有職者の内訳は, ブルーカラー系職種（土木, 建築 作業員，運転手，工員など現業系や技能系の職種） に就いていた者が67名（91\%）に対して，ホワイト カラー系職種（公務員など事務に従事する職種や営 業職）の者は 7 名のみであった. 本研究では, 有職 か無職（学生を含む）のいずれかにコード化するこ とで分析した。

最終学歴の扱いについて, 高校在学中であれば最 終学歴は中学卒業として作成した. データの最終学 歴に関する分布をみると, 中学卒業以下が64名（51 $\%)$, 高校中退が 10 名 $(8 \%)$, 高校卒業が39名（31 $\%)$, 短期大学 - 専門学校中退が 2 名 $(2 \%)$, 短期 大学・専門学校卒業が 9 名 (7\%), 大学卒業が 1 名 であった. なお, 本研究では義務教育を超えた学歴 を有するか否か（高校中退以下・高校卒業以上）で 分類した.

婚姻状態は，未婚者の放火犯が75名 $(60 \%)$, 既 婚者が 35 名 $(28 \%)$, 離婚若しくは死別した者が 15 名 (12\%) であった. 本研究では, 便宜上未婚者, 既婚者, 離婚・死別者にコード化し，分析を行っ た．子供を有する放火犯は21名（17\%）であった。 親と同居していた放火犯は55名(44\%)であった。 コード化は，親との同居あり・なしの 2 值で行っ た.

精神疾患を有していた者は24名（19\%）であった が，そのうち知的障害が 7 名, 統合失調症が 3 名, うつ病が 3 名, アルコール中毒が 2 名であった．本 分析に際しては, 精神疾患あり・なしとコード化し た上で分析を実施した。なお，事件資料内の精神疾 患に関する記載は警察官によるものであり，実際の 診断名と異なる可能性がある.

放火犯に抢ける哭煙者の人数は，60名（48\%）で あった．契煙者は着火道具として用いられやすいラ イターを所持していることが多いであろうことから 本研究でこの変数を扱った.

また，過去に何らかの犯罪に及んで検挙された者 は61名 (49\%) であった。中でも，窃盗歴を有する 者が49名（39\%）と最も多く, 次いで放火歴を有す 
る者が17名 (14\%) であった。そのため, 本研究で は，放火歴と窃盗歴の有無をそれぞれ扱った。

本研究では緒言で述べたように，犯行動機は変遷 する可能性があることから分析に用いなかった．た だし，連続放火犯にとっての主だった犯行動機を分 類したところ，榣憤晴らしの放火犯で84名(67\%)， 逆恨みの放火に及んだ者が23名（18\%），犯罪の証 拠を隠蔽するために放火した者が10名 $(8 \%)$, 残り 8 名（6\%）は愉快犯に分類できた.

\section{放火形態}

次の放火形態については 5 件中 1 件でも確認され れば，その放火犯がその行動をとったものとして扱 った. 用いた变数は, (1)下見・徘徊, (2)油類の使 用, (3)媒介物の使用と入手方法, (4)建造物への侵 入, (5)知人に対する放火, (6)同一場所への放火, (7) 犯行時の飲酒, 8現場への戻り, (9)警察消防への通 報, (10)移動手段の10变数である.

26名（21\%）の放火犯が，犯行前に下見や徘徊を 行っていた.

油類を用いて放火した者は26名(21\%)であった。 灯油を使用した者が最も多く21名（油類使用の81 $\%$ ，次いでガソリンを使用した者が多かった（油 類使用の $8 \%$ ).

放火するために何らかの媒介物を用いた者は105 名 $(84 \%)$ で，105名のうち，媒介物を現場で調達 した者は75名（媒介物利用の $71 \%$ ， あらかじめ犯 行前に準備した者は30名（媒介物利用の $29 \%$ ）であ った。媒介物の内訳 $(n=105)$ は，新聞雑誌など 書籍で $21 \%$ ，ポスターやティッシュペーパーなどの 紙類が $20 \%$ ，段ボール箱が $14 \%$ であった。その他，

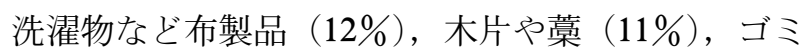
袋（11\%）といった媒介物がみられた。媒介物に関 する変数は, 媒介物なし・媒介物あり(現場調達) . 媒介物あり（事前準備）の 3 カテゴリで分析を行っ た。

建造物へ侵入した放火犯は34名 (27\%) 打り，そ のうち一般住宅に侵入した者が最も多く（建造物侵 入の $67 \%)$, 次いでアパートなどの共同住宅が多か った（建造物侵入の $17 \%$ ）。

本データによると，知人を対象とした放火犯は 28 名 $(22 \%)$ であり, 面識のない人物による割合の方
が高かった。

同一場所へ放火した者は43名（34\%）であった。

また，24名（19\%）の放火犯が犯行前に飲酒をし ていた.

放火した後に現場に戻ってきた放火犯は51名（41 \%)であった。

放火後に警察消防へ通報した者は13名（10\%）で あった。

移動手段については，自転車を使用した者が40名 （32\%）と最も多かった。自動車使用の割合は $31 \%$ （39名）で先行研究10)に比べて高い割合を示した.

また，4名（3\%）の久が自動二輪車を使用してい た。なお，本研究では自動車および自動二輪車の使 用, 自転車の使用, 徒歩の 3 つにコード化し，分析 を行った。

\section{分析手法}

本研究では, 放火犯の類型を抽出するためにカテ ゴリカル主成分分析（Categorical principal components analysis: CATPCA）を実施した ${ }^{13-17)}$.

CATPCA は多次元データ解析法の中でも名義尺 度抢よび順序尺度を扱うのに適した統計手法であ る。本研究では年齢層を順序尺度，それ以外を名義 尺度として扱ったことから，この分析手法を採用し た. CATPCA は, 複数の変数に潜在する次元を抽 出するのに加え，それらの次元に沿って各变数を成 分負荷として得点化し，また各変数のカテゴリをカ テゴリ数量として得点化することができる。さら に，成分負荷とカテゴリ数量から算出されるべクト ル座標を基にして，各放火犯にはオブジェクトスコ アとして得点が付与される．そのため，オブジェク トスコアの正負から放火犯を分類することができ る。そこで，本研究ではまず前述した11の放火犯の 属性を基に CATPCA を実施することで次元（放火 犯の類型）を抽出し，その次元を解釈した。続い て，オブジェクトスコアを基に各放火犯を分類し， 各群における放火犯の特徵をべクトル座標の布置関 係から検討した．次に，CATPCAによって分類さ れた群間で放火形態を検討するために，本研究では 階層的対数線形モデルによる分析（以下，対数線形 分析とする）を実施した。

対数線形分析は, $\chi^{2}$ 検定と同様にカテゴリカル 
データに用いられる手法であるが，3要因以上の仮 説検定が可能である ${ }^{18-20)}$. 従って, 後述のような 3 元分割のクロス集計表に適した分析手法であること から，これを採用した。なお，モデルの採択に際し ては，有意水準 5\%で棄却されなかったモデルを採
択の候補とした上で，さらに赤池情報量基準 (AIC: Akaike information criteria) ${ }^{21)}$ が最も低い最 適なモデルを採択した。続いて，各セルにおける標 準化残差を算出し，採択したモデルによって予測さ れる期待度数と本研究で得られた観測度数の乘離の

Table 1 Categorical principal components analysis (CATPCA) by the characteristic of the 125 arsonists.

\begin{tabular}{|c|c|c|c|c|}
\hline $\begin{array}{l}\text { Arsonist variables and } \\
\text { Subordinate categories }\end{array}$ & $N(\%)$ & $\begin{array}{c}\text { Category } \\
\text { quantifications }\end{array}$ & $\begin{array}{c}\text { Component } \\
\text { loadings } \\
\text { (Dimension 1) }\end{array}$ & $\begin{array}{c}\text { Component } \\
\text { loadings } \\
\text { (Dimension 2) }\end{array}$ \\
\hline \multicolumn{5}{|l|}{ Gender } \\
\hline Male & $109(87)$ & 0.38 & \multirow{2}{*}{0.51} & \multirow{2}{*}{-0.27} \\
\hline Female & $16(13)$ & -2.61 & & \\
\hline \multicolumn{5}{|l|}{ Age } \\
\hline $14-19$ & $15(12)$ & -1.70 & \multirow{5}{*}{-0.55} & \multirow{5}{*}{-0.53} \\
\hline 20-29 & $34(27)$ & -0.40 & & \\
\hline $30-39$ & $29(23)$ & -0.40 & & \\
\hline $40-49$ & $25(20)$ & 0.51 & & \\
\hline $50+$ & $22(18)$ & 1.72 & & \\
\hline \multicolumn{5}{|l|}{ Employment } \\
\hline Unemployed & $51(41)$ & -1.21 & \multirow{2}{*}{-0.20} & \multirow{2}{*}{0.17} \\
\hline Employed & $74(59)$ & 0.83 & & \\
\hline \multicolumn{5}{|l|}{ Education } \\
\hline Compulsory education level & $74(59)$ & 0.83 & \multirow{2}{*}{0.26} & \multirow{2}{*}{-0.46} \\
\hline Higher level & $51(41)$ & -1.21 & & \\
\hline \multicolumn{5}{|l|}{ Marital status } \\
\hline Unmarried & $75(60)$ & 0.81 & \multirow{3}{*}{0.79} & \multirow{3}{*}{-0.08} \\
\hline Married & $35(28)$ & -1.30 & & \\
\hline Divorced or lost & $15(12)$ & -1.04 & & \\
\hline \multicolumn{5}{|l|}{ Parental status } \\
\hline No children & $104(83)$ & 0.45 & \multirow{2}{*}{0.75} & \multirow{2}{*}{-0.27} \\
\hline Custodial parent & $21(17)$ & -2.23 & & \\
\hline \multicolumn{5}{|l|}{ Living with parent $(s)$} \\
\hline None & $70(56)$ & 0.89 & \multirow{2}{*}{-0.56} & \multirow{2}{*}{-0.62} \\
\hline Any & $55(44)$ & -1.13 & & \\
\hline \multicolumn{5}{|l|}{ Mental problem } \\
\hline None & $101(81)$ & 0.49 & \multirow{2}{*}{0.11} & \multirow{2}{*}{-0.06} \\
\hline Any & $24(19)$ & -2.05 & & \\
\hline \multicolumn{5}{|l|}{ Smoking } \\
\hline None & $65(52)$ & -0.96 & \multirow{2}{*}{0.10} & \multirow{2}{*}{-0.13} \\
\hline Any & $60(48)$ & 1.04 & & \\
\hline \multicolumn{5}{|l|}{ Criminal record of arson } \\
\hline None & $108(86)$ & 0.40 & & \\
\hline Any & $17(14)$ & -2.52 & -0.06 & 0.59 \\
\hline Criminal record of theft & & & & \\
\hline None & $76(61)$ & 0.80 & & 065 \\
\hline Any & $49(39)$ & -1.25 & & 0.05 \\
\hline
\end{tabular}


度合いを検討することで, モデル採択の適切さを確 認した。ささらに，採択されたモデルにおけるパラ メータの推定值を算出し, 要因間の関連度を検討し た。

\section{結 果}

\section{連続放火犯に関する特性の抽出と分類}

放火犯の11属性を基に CATPCAを行った結果, 固有值 2.20 の第 1 次元 (Cronbach $の \alpha=0.60)$ と 固有值 1.85 の第 2 次元 $($ Cronbach $の \alpha=0.51)$ が 得られた. 各放火犯属性におけるカテゴリ数量およ び各変数の成分負荷を Table 1 に示す. Table 1 の 第 1 次元の成分負荷によると, 婚姻状態, 子供の有 無，親との同居，年齢層，性別に関する变数の絶対 值が比較的高かった．このことから，この次元は社 会的な自立性といった放火犯の特性を示す軸である と解釈した。なお，性別については，女性の放火犯 は既婚者で子供を有している者が多いのに対して， 男性の放火犯では子供がいない傾向があることが成 分負荷の高さに結びついたと考えられる．後述の Fig. 1 では，それを示すような布置関係が得られて いる，また，第 2 次元では，穷盗歴，親との同居， 放火歴, 年齢層といった変数の絶対值が高い。窃盗 歴と放火歴といった犯罪歴に関する変数がみられる ことから, 第 2 次元は犯罪深度といった放火犯の特 性を示していると解釈した.

この 2 つ次元を軸として分類される 4 象限と 4 象限に括ける各放火犯のオブジェクトスコアの分布 から，それぞれの放火犯を 4 分類した. 人数の内訳 は, 高自立性 - 深犯罪深度群で28名, 高自立性 - 浅 犯罪深度群で24名, 低自立性・深犯罪深度群で29 名，低自立性・浅犯罪深度群で44名であった。

続いて，放火犯属性のベクトル座標を 2 次元上に 布置し（Fig. 1)，それぞれの群における放火犯の 属性を布置関係から検討した（Fig. 1の各カテゴリ の詳細については付録 $\mathrm{A}$ 参照)，なお，各群の放火 犯属性を Table 2 に示す. Fig. 1 の第 1 次元は社会 的な自立性を示し，第 2 次元は犯罪深度を示してい る。まず，Fig. 1 の第 1 象限（右上）は低自立性・ 浅犯罪深度群の 44 名が布置された次元である. 象限 内に布置された变数からこの群の放火犯が10代から

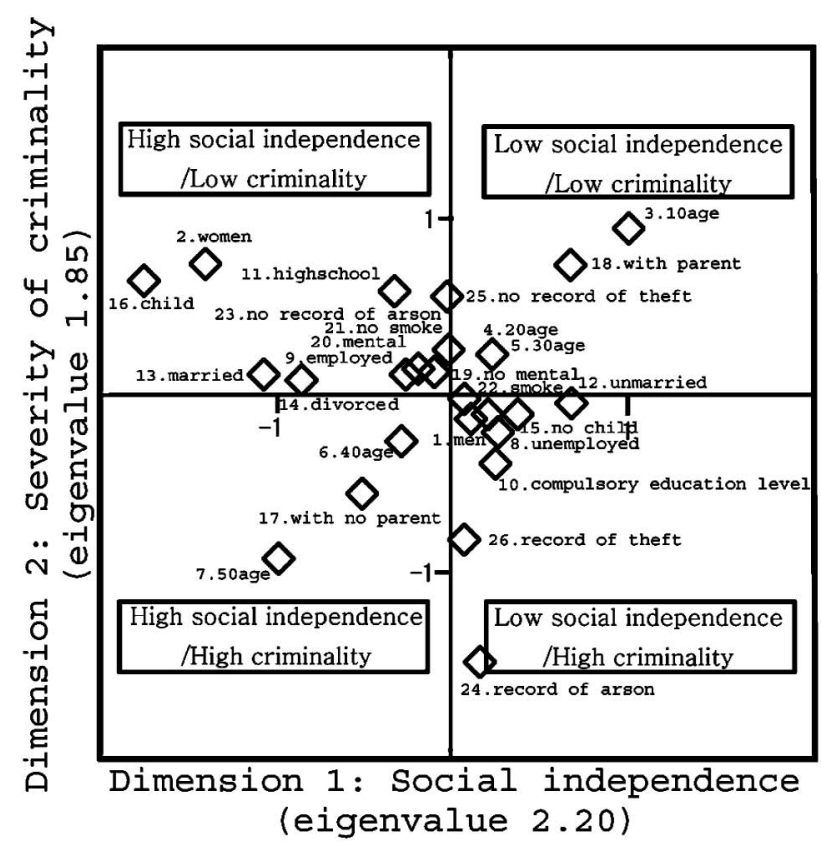

Fig. 1 Configuration of each category of variables of serial arsons by categorical principal components analysis (CATPCA).

30代の若年層で，親と同居しているといった特徵の あることが分かる．Table 2 によると，この群では 窃盗歴や放火歴のない未婚者が多くの割合を占めて いた。 一方，対角の次元である第 3 象限（左下）を みると，40代抢よび50代以上，親と同居していない といった変数が布置されており, 高自立性・深犯罪 深度群（28名）の特徴を示している. また，この群 の特徵として，窃盗歴を有する者の割合が高いとい った特徵もみられた（Table 2)．Fig. 1 の第 2 象限 （左上）は高自立性・浅犯罪深度群（24名）の放火 犯が該当し，既婚者で子供を持つ女性といった特徵 がみられる. 加えて, 有職者, 最終学歴が高校卒業 以上，窃盗歴打よび放火歴がない者が多く占めてい た（Table 2)。他群と比較すると，女性比（42\%） および精神疾患等を有する者 (33\%) が相対的に多 かった（Table 2). 補足事項として，この群に抢け る平均年齢は36.9歳（20代が最も多かった）であっ た。これに対して，低自立性・深犯罪深度群 (29名) に対応する対角の次元の第 4 象限(右下)をみると， 放火歴や窃盗歴があるのが特徵である. Table 2 に よると，この群の放火犯はすべて男性であるのに加 
Table 2 Characteristics of serial arsonists in each group.

\begin{tabular}{|c|c|c|c|c|}
\hline \multirow[b]{2}{*}{ Arsonist characteristics } & \multicolumn{4}{|c|}{ Frequency and percentage of each group } \\
\hline & $\begin{array}{l}\text { High social } \\
\text { / High criminal } \\
n=28(\%)\end{array}$ & $\begin{array}{l}\text { High social } \\
\text { /Low criminal } \\
n=24(\%)\end{array}$ & $\begin{array}{l}\text { Low social } \\
\text { /High criminal } \\
n=29(\%)\end{array}$ & $\begin{array}{l}\text { Low social } \\
\text { Low criminal } \\
n=44(\%)\end{array}$ \\
\hline \multicolumn{5}{|l|}{ Gender } \\
\hline Male & $24(86)$ & $14(58)$ & $29(100)$ & $42(95)$ \\
\hline Female & $4(14)$ & $10(42)$ & $0(0)$ & $2(5)$ \\
\hline \multicolumn{5}{|l|}{ Age } \\
\hline $14-19$ & $0(0)$ & $1(4)$ & $1(3)$ & $13(30)$ \\
\hline $20-29$ & $4(14)$ & $10(42)$ & $8(28)$ & $12(27)$ \\
\hline $30-39$ & $3(11)$ & $5(21)$ & $7(24)$ & $14(32)$ \\
\hline $40-49$ & $7(25)$ & $6(25)$ & $7(24)$ & $5(11)$ \\
\hline $50+$ & $14(50)$ & $2(8)$ & $6(21)$ & $0(0)$ \\
\hline \multicolumn{5}{|l|}{ Employment } \\
\hline Unemployed & $10(36)$ & $6(25)$ & $12(41)$ & $23(52)$ \\
\hline Employed & $18(64)$ & $18(75)$ & $17(59)$ & $21(48)$ \\
\hline \multicolumn{5}{|l|}{ Education } \\
\hline Compulsory education level & $20(71)$ & $5(21)$ & $25(86)$ & $24(55)$ \\
\hline Higher level & $8(29)$ & $19(79)$ & $4(14)$ & $20(45)$ \\
\hline \multicolumn{5}{|l|}{ Marital status } \\
\hline Unmarried & $4(14)$ & $2(8)$ & $28(97)$ & $41(93)$ \\
\hline Married & $16(57)$ & $17(71)$ & $1(3)$ & $1(2)$ \\
\hline Divorced or lost & $8(29)$ & $5(21)$ & $0(0)$ & $2(5)$ \\
\hline \multicolumn{5}{|l|}{ Parental status } \\
\hline No children & $21(75)$ & $10(42)$ & $29(100)$ & $44(100)$ \\
\hline Custodial parent & $7(25)$ & $14(58)$ & $0(\quad 0)$ & $0(\quad 0)$ \\
\hline \multicolumn{5}{|l|}{ Living with parent $(\mathrm{s})$} \\
\hline None & $27(96)$ & $16(67)$ & $24(83)$ & $3(7)$ \\
\hline Any & $1(4)$ & $8(33)$ & $5(17)$ & $41(93)$ \\
\hline \multicolumn{5}{|l|}{ Mental problem } \\
\hline None & $25(89)$ & $16(67)$ & $24(83)$ & $36(82)$ \\
\hline Any & $3(11)$ & $8(33)$ & $5(17)$ & $8(18)$ \\
\hline \multicolumn{5}{|l|}{ Smoking } \\
\hline None & $19(68)$ & $12(50)$ & $8(28)$ & $26(59)$ \\
\hline Any & $9(32)$ & $12(50)$ & $21(72)$ & $18(41)$ \\
\hline \multicolumn{5}{|l|}{ Criminal record of arson } \\
\hline None & $24(86)$ & $24(100)$ & $17(59)$ & $43(98)$ \\
\hline Any & $4(14)$ & $0(0)$ & $12(41)$ & $1(2)$ \\
\hline \multicolumn{5}{|l|}{ Criminal record of theft } \\
\hline None & $9(32)$ & $23(96)$ & $7(24)$ & $37(84)$ \\
\hline Any & $19(68)$ & $1(4)$ & $22(76)$ & $7(16)$ \\
\hline
\end{tabular}

え，高校中退以下，親と同居している独身，契煙習 慣がある，窃盗歴を有する者の占める割合がそれぞ れ高かった．他群と比較した場合，放火歴を有する 者 $(41 \%)$ が相対的に多いといった特徵もみられた。

\section{特性ごとの放火形態}

特性（自立性と犯罪深度）を基に分類した場合の それぞれの放火形態については, Table 3 のとおり である（対数線形分析の詳細な結果は，付録 B お 
Table 3 Offence characteristics in each group.

\begin{tabular}{|c|c|c|c|c|c|}
\hline \multirow[b]{2}{*}{ Offence characteristics } & \multicolumn{4}{|c|}{ Frequency and percentage of each group } & \multirow[b]{2}{*}{$\begin{array}{l}\text { selected } \\
\left.\text { model }^{\mathrm{a}}\right)\end{array}$} \\
\hline & $\begin{array}{l}\text { High social } \\
\text { / High criminal } \\
n=28(\%)\end{array}$ & $\begin{array}{l}\text { High social } \\
\text { /Low criminal } \\
n=24(\%)\end{array}$ & $\begin{array}{l}\text { Low social } \\
\text { / High criminal } \\
n=29(\%)\end{array}$ & $\begin{array}{l}\text { Low social } \\
\text { /Low criminal } \\
n=44(\%)\end{array}$ & \\
\hline \multicolumn{6}{|c|}{ Examination beforehand $[\mathrm{C}]$} \\
\hline None & $19(68)$ & $20(83)$ & $27(93)$ & $33(75)$ & \multirow{2}{*}[\mathrm{A}^{\mathrm{b})}\mathrm{B}^{\mathrm{c})}\mathrm{C}]{} \\
\hline Any & $9(32)$ & $4(17)$ & $2(7)$ & $11(25)$ & \\
\hline \multicolumn{6}{|l|}{ Oil for arsons $[\mathrm{D}]$} \\
\hline None & $22(79)$ & $13(54)$ & $22(76)$ & $42(95)$ & \multirow{2}{*}[\mathrm{ABD}]{} \\
\hline Any & $6(21)$ & $11(46)$ & $7(24)$ & $2(5)$ & \\
\hline \multicolumn{6}{|l|}{ Medium for arsons $[\mathrm{E}]$} \\
\hline None & $4(14)$ & $4(17)$ & $2(7)$ & $10(23)$ & \multirow{3}{*}[\mathrm{A}]{$[\mathrm{BE}]$} \\
\hline $\begin{array}{l}\text { Any supplying on the } \\
\text { spot }\end{array}$ & $20(71)$ & $9(38)$ & $21(72)$ & $25(57)$ & \\
\hline $\begin{array}{l}\text { Any preparations in } \\
\text { advance }\end{array}$ & $4(14)$ & $11(46)$ & $6(21)$ & $9(20)$ & \\
\hline \multicolumn{6}{|c|}{ Intrusion into a dwelling $[F]$} \\
\hline None & $20(71)$ & $17(71)$ & $18(62)$ & $36(82)$ & \multirow{2}{*}[\mathrm{A}]{$[\mathrm{B}][\mathrm{F}]$} \\
\hline Any & $8(29)$ & $7(29)$ & $11(38)$ & $8(18)$ & \\
\hline \multicolumn{6}{|l|}{ Target known $[\mathrm{G}]$} \\
\hline None & $21(75)$ & $16(67)$ & $27(93)$ & $33(75)$ & \multirow{2}{*}[\mathrm{AG}]{$[\mathrm{BG}]$} \\
\hline Any & $7(25)$ & $8(33)$ & $2(7)$ & $11(25)$ & \\
\hline \multicolumn{6}{|l|}{ Same place $[\mathrm{H}]$} \\
\hline None & $19(68)$ & $13(54)$ & $24(83)$ & $26(59)$ & \multirow{2}{*}[\mathrm{A}]{$[\mathrm{BH}]$} \\
\hline Any & $9(32)$ & $11(46)$ & $5(17)$ & $18(41)$ & \\
\hline \multicolumn{6}{|c|}{ Drinking alcohol before arson $[\mathrm{I}]$} \\
\hline None & $20(71)$ & $21(88)$ & $20(69)$ & $40(91)$ & \multirow{2}{*}[\mathrm{A}]{$[\mathrm{BI}]$} \\
\hline Any & $8(29)$ & $3(13)$ & $9(31)$ & $4(9)$ & \\
\hline \multicolumn{6}{|l|}{ Return to the scene $[\mathrm{J}]$} \\
\hline None & $12(43)$ & $15(63)$ & $19(66)$ & $28(64)$ & \multirow{2}{*}[\mathrm{A}]{$[\mathrm{B}][\mathrm{J}]$} \\
\hline Any & $16(57)$ & $9(38)$ & $10(34)$ & $16(36)$ & \\
\hline \multicolumn{6}{|l|}{ Emergency calls $[\mathrm{K}]$} \\
\hline None & $24(86)$ & $22(92)$ & $26(90)$ & $40(91)$ & \multirow{2}{*}[\mathrm{A}]{$[\mathrm{B}][\mathrm{K}]$} \\
\hline Any & $4(14)$ & $2(8)$ & $3(10)$ & $4(9)$ & \\
\hline \multicolumn{6}{|l|}{ Transportation $[\mathrm{L}]$} \\
\hline Walking & $11(39)$ & $12(50)$ & $8(28)$ & $11(25)$ & \multirow{4}{*}[\mathrm{AL}]{$[\mathrm{B}]$} \\
\hline Bicycle & $6(21)$ & $3(13)$ & $16(55)$ & $15(34)$ & \\
\hline Motorcycle & $0(0)$ & $0(0)$ & $1(3)$ & $3(7)$ & \\
\hline Car & $11(39)$ & $9(38)$ & $4(14)$ & $15(34)$ & \\
\hline
\end{tabular}

a) The author selected models in line with following criteria: 1) level of significance of model was over 5\% and 2) AIC (Akaike information criteria) was the lowest among these models.

b) $[\mathrm{A}]$ indicates variable of social independence of serial arsonists.

c) $[\mathrm{B}]$ indicates variable of the degree of criminality of serial arsonists.

よび付録 $\mathrm{C}$ 参照)。なお，自立性と犯罪深度の両者 は CATPCA によって得られた異なる特性であるこ とが分かっていることから，モデル採択の際は両者
の関連性については検討しなかった。

Table 3 によると，放火前に下見や徘䧃を行った 放火犯の割合は，高自立性・深犯罪深度群で最も高 
い $(32 \%)$. 下見・徘徊に関して，3 要因の対数線 形分析を行ったところ，飽和モデル（[自立性×犯 罪深度 $\times$ 下見・徘徊]）が採択された。このことか ら，4群の中では, 高自立性・深犯罪深度群の放火 犯が下見や徘徊を最も行うことが示された.

油類の使用について，3 要因の対数線形分析を行 った結果, 飽和モデル（[自立性 $\times$ 犯罪深度 $\times$ 油類 の使用]）が採択された。つまり，Table 3 が示す ように，4群の中では, 高自立性・浅犯罪深度群の 放火犯は油類を使用する割合が相対的に高かった (46\%).

媒介物の使用若しくは入手方法については，一変 数独立モデル ([犯罪深度 $\times$ 媒介物の入手 $][$ 自立性 $])$ が採択され，Table 3 が示すように，犯罪深度が深 い者は現場調達することが多く，犯罪深度が浅い者 は媒介物を用いない割合が相対的に高いことが分か った $\left(\mathrm{G}^{2}(5)=8.25, p=.14, \mathrm{AIC}=-1.75\right)$.

「建造物への侵入」に関しては, 3 変数独立モデ ルが採択され，各変数間に関連性は認められなかっ た $\left(\mathrm{G}^{2}(4)=6.05, p=.20, \mathrm{AIC}=-1.95\right)$.

また，知人に対する放火については，条件付き独 立モデル（[自立性 $\times$ 知人に対する放火］［犯罪深度 ×知人に対する放火]）が採択された。つまり，自 立性が高いほど，また犯罪深度が浅いほど知人に対 して放火する傾向があることが示された $\left(\mathrm{G}^{2}(2)=\right.$ $4.54, p=.10, \mathrm{AIC}=0.54)$.

「同一場所に放火する」に関して，犯罪深度が浅 い2 群の放火犯が同一場所に放火する割合が高かっ た (Table 3).これに関して，3 要因の対数線形分 析を実施した結果，一変数独立モデル（[犯罪深度 $\times$ 同一場所への放火］［自立性）が採択されたこと から，犯罪深度が浅い放火犯は同一場所へ放火する 傾向が相対的に高かったといえよう $\left(\mathrm{G}^{2}(3)=4.32\right.$, $p=.23, \mathrm{AIC}=-1.68)$.

犯行時の飲酒に関して，3要因の対数線形分析を 実施したところ, 一变数独立モデル（[犯罪深度 $\times$ 犯行時の飲酒］［自立性］）が採択された（ $\mathrm{G}^{2}(3)=$ $2.68, p=.44, \mathrm{AIC}=-3.32)$. このことから, Table 3 でも示すと抢り, 犯罪深度が深い者ほど飲酒して 犯行に及ぶ傾向がみられた。

「放火後の現場戻り」および「警察消防への通報」
については，3 変数独立モデルが採択されたため, 各変数間に関連性はみられなかった $\left(\mathrm{G}^{2}(4)=3.06\right.$, $p=.55, \mathrm{AIC}=-4.94 ; \mathrm{G}^{2}(4)=6.43, p=.17, \mathrm{AIC}=$ $-1.57)$.

最後に，移動手段に関する対数線形分析では，一 変数独立モデル（[自立性 $\times$ 移動手段 $][$ [犯罪深度 $])$ が採択された $\left(\mathrm{G}^{2}(7)=8.63, p=.28, \mathrm{AIC}=-\right.$ 5.37).このことから, Table 3 が示すように, 自立 性が高い放火犯は比較的自動車若しくは徒歩で移動 する者が多いのに対し，自立性が低い放火犯は自転 車で移動する者が多いことが示された。

以上の放火形態の分析に際しては，モデル採択 後, 標準化残差を算出し, 観測度数に適合したモデ ルであることを確認した。

\section{考 察}

本研究では, 放火犯の属性から社会的な自立性と 犯罪深度といった特性に対応する次元が抽出され た. 両特性は放火犯像ともいうべき骨格を表してい る. 社会的自立性の高い放火犯は既婚者で, 子供が いて，親と同居して抢らず，比較的年齢が高いとい った像である.これらの特徴から，このような放火 犯は比較的社会経験が豊富であることが予想され る.したがって，社会的自立性の高い放火犯は低い 者に比べて, 日常においてもコミュニケーション能 力が高いなど社会的スキル22) も高い可能性が考えら れる. また, 本研究では放火歴と窃盗歴の久を扱っ たが，犯罪深度の深い放火犯は他の犯罪歴も有して いるかもしれない. 今後は両特性と他の放火犯属性 との関連性を検討することで，この放火犯像をさら に深めることができよう。

また，これら特性によって放火犯を 4 つに分類す ることができた．各群における放火犯属性と放火形 態は次のとおりである。

\section{(1) 高自立性 ·深犯罪深度群}

（放火犯属性） 40 代以上，親と同居していな い，また，窃盗歴を有する放火犯が多く占めて いた。

（放火形態）媒介物を現場で調達する，また自 動車使用若しくは徒歩で移動する放火犯の占め る割合が高かった．他の群と比較すると, 犯行 
前に飲酒している者が相対的に多かった。

(2) 高自立性 · 浅犯罪深度群

（放火犯属性）この群では, 最終学歴が高校卒 業以上, 既婚者で子供を有する, 放火歴や窃盗 歴がない，有職者といった割合が高かった。ま た，4群の中で比較すると，女性比 (42\%) や 精神疾患等を有する者の割合（33\%）が高いと いった特徵がみられた。

（放火形態） 飲酒して犯行に及ぶ者の割合が低 かった。 また，他の群と比べると，知人を対 象, 油類の事前準備, 同一場所への放火, 徒歩 移動がそれぞれ相対的に多かった。

\section{(3) 低自立性 · 深犯罪深度群}

（放火犯属性）男性の久の群で, 最終学歴が高 校中退以下，親と同居している独身者，喫煙習 慣がある，窃盗歴を有する者が多く占めてい た。 また，4群の中では，放火歴を有する者 (41\%)の割合が相対的に高かった.

（放火形態）知人を対象とすることは少なく， 下見や徘徊はしない，また媒介物を現場で調達 し，自転車で移動する放火犯が多かった。他の 群と比較すると, 犯行時に飲酒している放火犯 が占める割合が相対的に高かった。

\section{(4) 低自立性 · 浅犯罪深度群}

（放火犯属性）この群のほとんどが10代から30 代の若年層で，親と同居している独身者，また 放火歴や容盗歴がない者が多くの割合を占めて いた。

（放火形態）犯行時に飲酒していることは少な く，油類を使わない者が 9 割を占めるといった 特徵がみられた。 また, 他の群と比較して, 同 一場所に放火する者が相対的に多かった。

このように，本研究では放火犯の特性ごとで放火 形態に特徵がみられた。まず，社会的自立性の高い 放火犯に自動車を使用する者が多かった。この理由 として，これらの放火犯は有職者が多く, 車両を維 持するために必要な経費を支払うことができるもの と考えた.ただし, Fig. 1 をみると, 就業状態は社 会的自立性に対する影響力が相対的に小さいように 思われた。そこで, 社会的自立性の高低間で有職率 を検討したところ，この説明を補足するように社会
的自立性の低群（52\%）に比べて高群 $(69 \%)$ で有 職者が多い傾向がみられた $\left(\chi^{2}(1, N=125)=3.71\right.$, $p=0.054 ， \phi=-0.17)$. 屯た，犯罪深度が深い放火 犯は飲酒して犯行に及ぶ者が相対的に多いのに加 え，同一場所に放火する者が相対的に少ないといっ た特徵もみられた。これらの理由の 1 つとして, 放 火に対する心理的抵抗によって説明ができるかもし れない，例えば，犯罪深度と飲酒の関係について， 犯罪深度が深い者は放火への心理的抵抗が弱く，飲 酒をきっかけに脱抑制化することで，衝動的に放火 に及ぶと考えられる．一方，犯罪深度の浅い者は， 放火を始めとする犯罪行為そのものに対して心理的 抵抗が強いために，飲酒による脱抑制化の影響が相 対的に少なく，その結果飲酒して放火にいたるケー スが少なかったのではないだろうか。また，犯罪深 度と同一場所への放火の関連性については，仮説と して「犯罪深度の浅い者は，犯罪深度の深い者と比 べて，犯行への心理的抵抗がある一方で，逆恨みと いった特定の者を対象とする放火犯が相対的に多い ために，同一場所に対する放火が相対的に多くなっ た」ことが考えられる，そこで，参考までに本デー タをみたところ, 深犯罪深度群では逆恨みで放火に 及んだ者の割合が $12 \%$ であるのに対し，浅犯罪深度 群では24\%と高かった。ただし，両群間における統 計的な有意差はみられなかった $\left(\chi^{2}(1, N=125)=\right.$ 2.61, $p=0.11, \phi=0.15)$. このことから, これらの 仮説については今後もサンプル数を増やし検討する 必要があうう。

4 つの群の中でも, 特徵的なタイプとして高自立 性・浅犯罪深度群が挙げられる。この群の放火犯は 女性である割合が他の群に比べて相対的に高かっ た。女性比は 4 割程度であったものの, Wachi et $\left.a l .{ }^{4}\right)$ が示した女性の連続放火犯の年齢特徵（平均年 齢37.6歳，20代が最も多い）に類似している。 た，女性の連続放火犯は居住地から近接した狭い範 囲で放火に及ぶことが指摘されている( から，女性の割合が高かった高自立性・浅犯罪深度 群においても同様に，連続放火の地理的範囲が狭い といった傾向がみられるかもしれない，それを示す ように，この群では徒歩による移動が多かった．

以上の 4 群が得られたものの, 本研究では 
CATPCA に打けるCronbach の $\alpha$ が低かった（次 元 1 で 0.60 , 次元 2 で 0.51$)$. Cronbach $の \alpha$ は内的 整合性を示す指標であり，本研究における変数選択 の限界が表れている，ただし，犯人像推定研究では あくまで犯罪者と犯罪行動との関連性を探索し，発 見することが重要となる．加えて，CATPCA は本 研究ではあくまで放火犯を分類するための手法に過 ぎない.したがって，次元の解釈や次元自体の妥当 性に関して限界はあるものの, 分類後に $\mathrm{A}-\mathrm{C}$ の関 連性が見出せることができれば，その知見は有用で ある. 今後は本研究で用いた变数の取捨選択に加 え，他の変数を増やすことで再検討する必要があ る.

また，これらCATPCAによる分析の限界もさる ことながら，使用したサンプルの質的および量的限 界も挙げられる. 本研究では事件資料を基に作成し たデータを使用したが，元々事件資料は犯罪捜査の ために作成するものであり，分析のために作成され たものではない。したがって，A-C 研究で有用な 情報が含まれているとは限らない。また，本研究で 行った対数線形分析のモデル選択では AIC を基準 としたが，AIC はサンプル数に影響するとされて いる21)ことから，最適なモデル選択を行うためにも 今後はサンプル数を増やし，同様の分析によって試 行錯䛊する必要もあろう。

本研究のように犯罪者側の特徵を基に分類した $\mathrm{A}-\mathrm{C}$ 研究は，犯人像推定に打いても有益な知見々 なりうる，例えば，ある未解決事件が油類を撒いて 放火したという事案であったとする．この特徵は高 自立性・浅犯罪深度群による放火形態の特徵であ り，この群に女性の放火犯が多いことから，この犯 人が女性である可能性が高くなるかもしれない。た だし, 本研究の結果は「自立性が高く犯罪深度が浅 い連続放火犯の場合に，油類を事前に準備して放火 に及ぶ可能性が高い」という関連性を示したもので ある.これに対して，実践に打ける犯人像推定では 「油類を用いて放火された事件の場合, 高自立性 · 浅犯罪深度群に該当する確率」を検討することか ら, 本研究の結果とは逆の命題を解く必要がある. 確率論的に「A の場合， B である確率」と「Bの場 合，Aである確率」は異なる，そのため，本研究
のような知見を犯人像推定で実際行うためには，い わゆるべイズ推定（逆確率）による計算が必要とな る23). その上で, その高自立性・浅犯罪深度群に該 当する確率上本研究で示した女性比 (42\%) から, 当該事件の放火犯が女性である確率を算出すること ができるようになる. 従来の犯人像推定が犯罪行動 を中心とした分析であったのは，犯罪行動からある 程度 A-C の関連性を発見することができたからで あろう。しかし, 本研究では犯罪行動による類型で は得られなかった $\mathrm{A}-\mathrm{C} の$ 関連性を, 犯罪者側の特 徵を基に分類することで見出すことができた。ま た，そのような $\mathrm{A}-\mathrm{C} の$ 関連性は，逆確率の概念を 用いることで犯人像推定に括いても有用な知見とな りうるであろう。

以上, 本研究では放火犯の特性と放火形態の関連 性について検討した. 今後は, 地理的プロファイリ ングや犯行予測といった実践を視野に, 放火犯の特 性と地理的要因（犯行移動距離など）若しくは時間 的要因（犯行間隔や時間帯）の関連性についてさら に知見を蓄積することで, 放火犯罪に抢ける $\mathrm{A}-\mathrm{C}$ 研究はより発展するものと思われる.

\section{引用文献}

1) Canter, D. and Youngs, D.: Investigative psychology: Offender profiling and the analysis of criminal action. pp. 396-398, Chichester, John Wiley and Sons (2009).

2) Canter, D. and Fritzon, K.: Differentiating arsonists: A model of firesetting actions and characteristics. Legal and Criminological Psychology, 3, 73-96 (1998).

3) Santtila, P., Häkkänen, H., Alison, L. and Whyte, C.: Juvenile firesetters: Crime scene actions and offender characteristics. Legal and Criminological Psychology, 8, 1-20 (2003).

4) Wachi, T., Watanabe, K., Yokota, K., Suzuki, M., Hoshino, M., Sato, A. and Fujita, G.: Offender and crime characteristics of female serial arsonists in Japan. Journal of Investigative Psychology and Offender Profiling, 4, 29-52 (2007).

5) Wachi, T., Watanabe, K., Yokota, K., Suzuki, 
M., Sato, A., Okamoto, D., and Fujita, G.: Crime scene behaviours and background characteristics of Japanese male serial arsonists. International congress of psychology and law, (9) (2007).

6）中田 修: 放火の犯罪心理. 金剛出版, 東京 (1977).

7）桐生正幸：最近18年間における田舎型放火の 検討. 犯罪心理学研究, 33(2), 17-26 (1995).

8) Canter, D. and Youngs, D.: Investigative psychology: Offender profiling and the analysis of criminal action. pp. 93, Chichester, John Wiley and Sons (2009).

9）上野 厚：都市型放火犯罪一放火犯罪心理分 析入門一。立花書房，東京 (2000).

10）鈴木 護：連続放火犯の犯人像と地理的プロ ファイリング。火災，49(4)，42-48（1999）。

11）鈴木 護: 連続放火の犯人像分析. 予防時報 225, 30-35 (2006).

12）田村雅幸, 鈴木 護: 連続放火の犯人像分析 1. 犯人居住地に関する円仮説の検討. 科学警 察研究所報告（防犯少年編）, 38 (1), 13-25 (1997) .

13) Gifi, A.: Nonlinear multivariate analysis. John Wiley and Sons, Chichester (1990).

14） Linting, M., Meulman, J. J., Groenen, P. J. F. and Van der Kooij, A. J.: Nonlinear principal components analysis: Introduction and application. Psychological Method, 12, 336-358 (2007).

15）足立浩平：多変量カテゴリカルデータの数量 化と主成分分析. 心理学評論, 43(4), 487-500 (2000).

16）石村貞夫：SPSS によるカテゴリカルデータ 分析の手順．東京図書，東京 (2005).

17）加藤千恵子, 石村貞夫 : 臨床心理 - 精神医学 のためのSPSS による統計処理. 東京図書, 東 京 (2007).

18) Christensen, R. A.: Log-Linear Models. Springer-verlag, NY (1990).

19) Knoke, D. K. and Burke, P. J.: Log-Linear Models; Quantitative Applications in the Social
Sciences. Sage publications, CA (1980).

20）太郎丸博：人文・社会科学のためのカテゴリ カル・データ解析入門. ナカニシヤ出版, 京都 (2005).

21）赤池弘次, 甘利俊一, 北川源四郎, 樺島祥 介, 下平英寿 (著), 室田一雄, 土谷隆 (編)： 赤池情報量規準 $\mathrm{AIC}$ 一モデリング・予測・知識 発見一，共立出版，東京 (2007).

22）菊池章夫：また思いやりを科学する一向社会 的行動の心理とスキル。川島書店, 東京 (1998).

23）小島寛之：確率的発想法 数学を日常に活か す．日本放送出版協会，東京（2004）.

\section{付録 A Fig. 1 の次元上に布置された放火 犯属性変数のカテゴリ}

性別：('1. men’ = “男性” ), ('2. women’ = '女性”) 年齢層 : ('3.10age' $=$ '10代' $), \quad(' 4.20 \mathrm{age}$ ' $=$ '20 代' ), ('5.30age' = '30代’ ), ('6.40age' $=$ '40代’ $),(' 7.50$ age' $=$ '50代以上’ $)$

就業状態：( '8. unemployed' = '無職（学生を含 む)’ ), ('9. employed’ = '有職’ $)$

最終学歴 : ('10. compulsory education level' = '高 校中退以下’ ), ('11. high school’ = ‘高 校卒業以上’)

婚姻状態 : ( '12. unmarried’ = ‘未婚’ ), ('13. married' = '既婚' $) ，($ '14. divorced' = '離 婚若しくは死別’ )

子供：('15. no child’ = ‘子供なし’)，（'16. child’ = ‘子供あり’)

親との同居 : ( '17. with no parent' = ‘親との同居な し’), ('18. with parent' = ‘親との同 居あり’)

精神疾患: ( '19. no mental’ = ‘精神疾患なし’), ('20. mental' = '精神疾患あり’)

妿煙習慣：( ‘21. no smoke’ = ‘喫煙習慣なし’), （'22. smoke’ = ‘喫煙習慣あり’)

放火歴 : ( '23. no record of arson'”放火歴なし’), ( '24. record of arson' = ‘放火歴あり’)

窃盗歴 : ( '25. no record of theft'”窃盗歴なし’), ('26. record of theft' = '窃盗歴あり') 


\section{付録 B 放火形態に関する対数線形分析の 結果（モデル採択）}

放火形態に関する対数線形分析のモデル採択結果 をTable A に示す．A は社会的自立性，B は犯罪
深度を示しており，その他の変数（C-L）について は表題のとおりである.なお， $\mathrm{G}^{2}$ は尤度比統計 量, $d f$ は自由度, $\alpha$ は有意確率, $\mathrm{AIC}$ は赤池情報 量基準 (Akaike information criteria) である.

Table A Results of selecting model in Log-liner analysis for each offence characteristics $(a-j)$.

a) Examination beforehand [C] b) Oil for arsons [D]

\begin{tabular}{lrrrrr}
\hline \multicolumn{1}{c}{ model } & \multicolumn{1}{c}{$\mathrm{G}^{2}$} & $\mathrm{df}$ & $\alpha$ & AIC & $\begin{array}{c}\text { selected } \\
\text { model }\end{array}$ \\
\hline$[\mathrm{ABC}]$ & 0 & 0 & & 0 & $*$ \\
{$[\mathrm{AC}][\mathrm{BC}]$} & 8.35 & 2 & $p<.05$ & 4.35 & \\
{$[\mathrm{AC}][\mathrm{B}]$} & 8.49 & 3 & $p<.05$ & 2.49 & \\
{$[\mathrm{~A}][\mathrm{BC}]$} & 9.29 & 3 & $p<.05$ & 3.29 & \\
{$[\mathrm{~A}][\mathrm{B}][\mathrm{C}]$} & 9.43 & 4 & $p<.05$ & 1.43 & \\
\hline
\end{tabular}

\begin{tabular}{lcccccc}
\hline \multicolumn{1}{c}{ model } & \multicolumn{1}{c}{$\mathrm{G}^{2}$} & $\mathrm{df}$ & $\alpha$ & $\mathrm{AIC}$ & $\begin{array}{c}\text { selected } \\
\text { model }\end{array}$ \\
\hline$[\mathrm{ABD}]$ & 0 & 0 & & 0 & $*$ \\
{$[\mathrm{AD}][\mathrm{BD}]$} & 11.91 & 2 & $p<.01$ & 7.91 & \\
{$[\mathrm{AD}][\mathrm{B}]$} & 12.16 & 3 & $p<.01$ & 6.16 & \\
{$[\mathrm{~A}][\mathrm{BD}]$} & 19.48 & 3 & $p<.01$ & 13.48 & \\
{$[\mathrm{~A}][\mathrm{B}][\mathrm{D}]$} & 19.74 & 4 & $p<.01$ & 11.74 & \\
\hline
\end{tabular}

c) Medium for arsons [E]

\begin{tabular}{lrrrrrr}
\hline \multicolumn{1}{c}{ model } & \multicolumn{1}{c}{$\mathrm{G}^{2}$} & $\mathrm{df}$ & $\alpha$ & AIC & $\begin{array}{c}\text { selected } \\
\text { model }\end{array}$ \\
\hline$[\mathrm{ABE}]$ & 0 & 0 & & \multicolumn{2}{c}{0} & \\
{$[\mathrm{AE}][\mathrm{BE}]$} & 7.11 & 3 & $p=.07$ & 1.11 & \\
{$[\mathrm{AE}][\mathrm{B}]$} & 13.48 & 5 & $p<.05$ & 3.48 & \\
{$[\mathrm{~A}][\mathrm{BE}]$} & 8.25 & 5 & $p=.14$ & -1.75 & $*$ \\
{$[\mathrm{~A}][\mathrm{B}][\mathrm{E}]$} & 14.63 & 7 & $p<.05$ & 0.63 & \\
\hline
\end{tabular}

d) Intrusion into a dwelling [F]

\begin{tabular}{lrrrrrr}
\hline \multicolumn{1}{c}{ model } & $\mathrm{G}^{2}$ & df & $\alpha$ & AIC & $\begin{array}{c}\text { selected } \\
\text { model }\end{array}$ \\
\hline$[\mathrm{ABF}]$ & 0 & 0 & & \multicolumn{2}{c}{0} \\
{$[\mathrm{AF}][\mathrm{BF}]$} & 3.94 & 2 & $p=.14$ & -0.05 & \\
{$[\mathrm{AF}][\mathrm{B}]$} & 5.93 & 3 & $p=.11$ & -0.07 & \\
{$[\mathrm{~A}][\mathrm{BF}]$} & 4.07 & 3 & $p=.25$ & -1.93 & \\
{$[\mathrm{~A}][\mathrm{B}][\mathrm{F}]$} & 6.05 & 4 & $p=.20$ & -1.95 & $*$ \\
\hline
\end{tabular}

e) Target known [G]

\begin{tabular}{lrrrrrr}
\hline \multicolumn{1}{c}{ model } & $\mathrm{G}^{2}$ & $\mathrm{df}$ & $\alpha$ & AIC & $\begin{array}{r}\text { selected } \\
\text { model }\end{array}$ \\
\hline$[\mathrm{ABG}]$ & 0 & 0 & & & 0 & \\
{$[\mathrm{AG}][\mathrm{BG}]$} & 4.54 & 2 & $p=.10$ & 0.54 & $*$ \\
{$[\mathrm{AG}][\mathrm{B}]$} & 7.24 & 3 & $p=.08$ & 1.24 & \\
{$[\mathrm{~A}][\mathrm{BG}]$} & 6.65 & 3 & $p=.08$ & 0.65 & \\
{$[\mathrm{~A}][\mathrm{B}][\mathrm{G}]$} & 9.34 & 4 & $p=.053$ & 1.34 & \\
\hline
\end{tabular}

f) Same place $[\mathrm{H}]$

\begin{tabular}{lrrrrrr}
\hline \multicolumn{1}{c}{ model } & $\mathrm{G}^{2}$ & $\mathrm{df}$ & $\alpha$ & AIC & $\begin{array}{c}\text { selected } \\
\text { model }\end{array}$ \\
\hline$[\mathrm{ABH}]$ & 0 & 0 & & 0 & \\
{$[\mathrm{AH}][\mathrm{BH}]$} & 3.67 & 2 & $p=.16$ & -0.33 & \\
{$[\mathrm{AH}][\mathrm{B}]$} & 8.24 & 3 & $p<.05$ & 2.24 & \\
{$[\mathrm{~A}][\mathrm{BH}]$} & 4.32 & 3 & $p=.23$ & -1.68 & $*$ \\
{$[\mathrm{~A}][\mathrm{B}][\mathrm{H}]$} & 8.89 & 4 & $p=.06$ & 0.89 & \\
\hline
\end{tabular}

g) Drinking alcohol before arson [I]

h) Return to the scene $[\mathrm{J}]$

\begin{tabular}{lrrrrrr}
\hline \multicolumn{1}{c}{ model } & $\mathrm{G}^{2}$ & $\mathrm{df}$ & $\alpha$ & $\mathrm{AIC}$ & $\begin{array}{c}\text { selected } \\
\text { model }\end{array}$ \\
\hline$[\mathrm{ABI}]$ & 0 & 0 & & \multicolumn{2}{c}{0} & \\
{$[\mathrm{AI}][\mathrm{BI}]$} & 2.46 & 2 & $p=.29$ & -1.54 & \\
{$[\mathrm{AI}][\mathrm{B}]$} & 10.18 & 3 & $p<.05$ & 4.18 & \\
{$[\mathrm{~A}][\mathrm{BI}]$} & 2.68 & 3 & $p=.44$ & -3.32 & $*$ \\
{$[\mathrm{~A}][\mathrm{B}][\mathrm{I}]$} & 10.40 & & 4 & $p<.05$ & 2.40 & \\
\hline
\end{tabular}

\begin{tabular}{lrrrrrr}
\hline \multicolumn{1}{c}{ model } & $\mathrm{G}^{2}$ & $\mathrm{df}$ & $\alpha$ & AIC & $\begin{array}{c}\text { selected } \\
\text { model }\end{array}$ \\
\hline$[\mathrm{ABJ}]$ & 0 & & 0 & & 0 & \\
{$[\mathrm{AJ}][\mathrm{BJ}]$} & 3.48 & 2 & $p=.18$ & -0.52 & \\
{$[\mathrm{AJ}][\mathrm{B}]$} & 4.48 & 3 & $p=.21$ & -1.52 & \\
{$[\mathrm{~A}][\mathrm{BJ}]$} & 5.43 & 3 & $p=.14$ & -0.57 & \\
{$[\mathrm{~A}][\mathrm{B}][\mathrm{J}]$} & 6.43 & & 4 & $p=.17$ & -1.57 & $*$ \\
\hline
\end{tabular}

i) Emergency calls [K]

\begin{tabular}{lrrrrrr}
\hline \multicolumn{1}{c}{ model } & $\mathrm{G}^{2}$ & $\mathrm{df}$ & $\alpha$ & AIC & $\begin{array}{r}\text { selected } \\
\text { model }\end{array}$ \\
\hline$[\mathrm{ABK}]$ & 0 & 0 & & 0 & \\
{$[\mathrm{AK}][\mathrm{BK}]$} & 2.54 & 2 & $p=.28$ & -1.46 & \\
{$[\mathrm{AK}][\mathrm{B}]$} & 2.93 & 3 & $p=.40$ & -3.07 & \\
{$[\mathrm{~A}][\mathrm{BK}]$} & 2.66 & 3 & $p=.45$ & -3.34 & \\
{$[\mathrm{~A}][\mathrm{B}][\mathrm{K}]$} & 3.06 & 4 & $p=.55$ & -4.94 & $*$ \\
\hline
\end{tabular}

j) Transportation [L]

\begin{tabular}{lrrrrrr}
\hline \multicolumn{1}{c}{ model } & $\mathrm{G}^{2}$ & $\mathrm{df}$ & $\alpha$ & AIC & $\begin{array}{c}\text { selected } \\
\text { model }\end{array}$ \\
\hline$[\mathrm{ABL}]$ & 0 & 0 & & \multicolumn{2}{c}{0} & \\
{$[\mathrm{AL}][\mathrm{BL}]$} & 5.68 & 4 & $p=.22$ & -2.32 & \\
{$[\mathrm{AL}][\mathrm{B}]$} & 8.63 & 7 & $p=.28$ & -5.37 & $*$ \\
{$[\mathrm{~A}][\mathrm{BL}]$} & 20.88 & 7 & $p<.01$ & 6.88 & \\
{$[\mathrm{~A}][\mathrm{B}][\mathrm{L}]$} & 23.84 & 10 & $p<.01$ & 3.84 & \\
\hline
\end{tabular}




\section{付録 C 放火形態に関する対数線形分析の} 結果（パラメー夕推定）

付録 B の Table A で採択された最適モデルにお ける交互作用項のパラメータ推定值を Table B に示 す. A は社会的自立性, $\mathrm{B}$ は犯罪深度を示してお
り, その他の変数（C-E, G-I, L) については表題 のとおりである.なお， 3 変数独立モデルが採択さ れた「建造物への侵入」，「現場への戻り」，抢よび 「警察消防への通報」の变数については分析を省略 した.

Table B Results of inferring parameters in Log-liner analysis for each offence characteristics ( $\mathrm{a}-\mathrm{g})$.

a) Examination beforehand [C]

\begin{tabular}{ccc}
\hline \multirow{2}{*}{$A$} & \multicolumn{3}{c}{$[\mathrm{AC}]$} \\
\cline { 2 - 3 } & None & Any \\
\hline High & -0.17 & 0.17 \\
Low & 0.17 & -0.17 \\
\hline \multirow{2}{*}{$\mathrm{B}$} & \multicolumn{3}{c}{$[\mathrm{BC}]$} \\
\cline { 2 - 3 } & None & Any \\
\hline High & 0.08 & -0.08 \\
Low & -0.08 & 0.08 \\
\hline
\end{tabular}

\begin{tabular}{cccc}
\hline \multirow{2}{*}{$\mathrm{A}$} & $\mathrm{B}$ & \multicolumn{2}{c}{$[\mathrm{ABC}]$} \\
\cline { 3 - 4 } & & None & Any \\
\hline High & High & -0.30 & 0.30 \\
High & Low & 0.30 & -0.30 \\
Low & High & 0.30 & -0.30 \\
Low & Low & -0.30 & 0.30 \\
\hline
\end{tabular}

b) Oil for arsons [D]

\begin{tabular}{ccc}
\hline \multirow{2}{*}{$\mathrm{A}$} & \multicolumn{3}{c}{$[\mathrm{AD}]$} \\
\cline { 2 - 3 } & None & Any \\
\hline High & -0.34 & 0.34 \\
Low & 0.34 & -0.34 \\
\hline \multirow{2}{*}{$\mathrm{B}$} & \multicolumn{3}{c}{$[\mathrm{BD}]$} \\
\cline { 2 - 3 } & None & Any \\
\hline High & -0.10 & 0.10 \\
Low & 0.10 & -0.10 \\
\hline
\end{tabular}

\begin{tabular}{cccc}
\hline \multirow{2}{*}{$\mathrm{A}$} & \multirow{2}{*}{$\mathrm{B}$} & \multicolumn{2}{c}{$[\mathrm{ABD}]$} \\
\cline { 3 - 4 } & None & Any \\
\hline High & High & 0.38 & -0.38 \\
High & Low & -0.38 & 0.38 \\
Low & High & -0.38 & 0.38 \\
Low & Low & 0.38 & -0.38 \\
\hline
\end{tabular}

c) Medium for arsons [E]

\begin{tabular}{cccc}
\hline B & \multicolumn{3}{c}{$[\mathrm{BE}]$} \\
\cline { 2 - 4 } & None & Any supplying & Any preparation \\
\hline High & -0.20 & 0.32 & -0.12 \\
Low & 0.20 & -0.32 & 0.12 \\
\hline
\end{tabular}

d) Target known [G]

\begin{tabular}{ccc}
\hline \multirow{2}{*}{$\mathrm{A}$} & \multicolumn{3}{c}{$[\mathrm{AG}]$} \\
\cline { 2 - 3 } & None & Any \\
\hline High & -0.16 & 0.16 \\
Low & 0.16 & -0.16 \\
\hline \multirow{2}{*}{$\mathrm{B}$} & \multicolumn{3}{c}{ [BG] } \\
\cline { 2 - 3 } & None & Any \\
\hline High & 0.18 & -0.18 \\
Low & -0.18 & 0.18 \\
\hline
\end{tabular}

e) Same place [H]

\begin{tabular}{ccc}
\hline \multirow{2}{*}{$\mathrm{B}$} & \multicolumn{3}{c}{$[\mathrm{BH}]$} \\
\cline { 2 - 3 } & None & Any \\
\hline High & 0.21 & -0.21 \\
Low & -0.21 & 0.21 \\
\hline
\end{tabular}

f) Drinking alcohol before arson [I]

\begin{tabular}{ccc}
\hline \multirow{2}{*}{$\mathrm{B}$} & \multicolumn{3}{c}{$[\mathrm{BI}]$} \\
\cline { 2 - 3 } & None & Any \\
\hline High & -0.33 & 0.33 \\
Low & 0.33 & -0.33 \\
\hline
\end{tabular}

g) Transportation [L]

\begin{tabular}{ccccc}
\hline \multirow{2}{*}{$A$} & \multicolumn{4}{c}{$[\mathrm{AL}]$} \\
\cline { 2 - 5 } & Walking & Bicycle & Motorcycle & Car \\
\hline High & 0.05 & -0.67 & 0 & -0.02 \\
Low & -0.05 & 0.67 & 0 & 0.02 \\
\hline
\end{tabular}

